\title{
Morphology, Thermal Behavior and Dynamic Rheological Properties of Wood Polypropylene Composites*
}

\author{
Diène Ndiaye $^{1 \#}$, Vincent Verney ${ }^{2,3}$, Haroutioun Askanian ${ }^{2,4}$, Sophie Commereuc ${ }^{2,4}$, Adams Tidjani ${ }^{5}$ \\ ${ }^{1}$ Section Physique Appliquée, Université Gaston Berger, Saint-Louis, Sénégal; ${ }^{2}$ Institut de Chimie de Clermont-Ferrand, Université \\ Blaise Pascal, Clermont-Ferrand, France; ${ }^{3} \mathrm{CNRS}$, UMR 6296, ICCF, Université Blaise Pascal, Aubière, France; ${ }^{4}$ Ecole Nationale \\ Supérieure de Chimie de Clermont-Ferrand, Université Blaise Pascal, Clermont-Ferrand, France; ${ }^{5}$ Département de Physique, Université \\ Cheikh Anta Diop, Dakar, Sénégal. \\ Email: \#diene.ndiaye @ugb.edu.sn
}

Received September $2^{\text {nd }}, 2013$; revised October $18^{\text {th }}, 2013$; accepted November $7^{\text {th }}, 2013$

Copyright (C) 2013 Diène Ndiaye et al. This is an open access article distributed under the Creative Commons Attribution License, which permits unrestricted use, distribution, and reproduction in any medium, provided the original work is properly cited.

\begin{abstract}
Wood polymer composites (WPCs) were made with pine and polypropylene matrix (PP). The composites were produced by melt blending in a Brabender at $180^{\circ} \mathrm{C}$. Characterization of the samples, with the aid of scanning electron microscopy supplemented by microscope photography, showed an improved dispersion of wood in the polymeric material in presence of polypropylene grafted with maleic anhydride (MAPP) or nanoclay. The use of the MAPP instead of clay seems to have enhanced the level of crystallinity in the composites for the same levels of wood loading and also accelerates the crystallization. Melt rheological measurements of neat PP and PP-wood composites were carried out at $180^{\circ} \mathrm{C}$ with an ARES Rheometer scientific mechanical spectrometer in oscillatory frequency. All the composites materials exhibit viscoelastic values greater than those for neat PP. The samples containing MAPP as comptabilizer show the higher Newtonian viscosity, however, the addition of a small concentration of nanoparticles like nanoclays does not improve the resulting melt viscoelastic behavior of the composite.
\end{abstract}

Keywords: Morphology; Thermal Behavior; Dynamic Rheological Properties; Wood Polypropylene Composites

\section{Introduction}

In recent years, thermoplastic composites reinforced with a natural component such as wood, sisal, jute, rice husk, and flax fiber have been found to show a lot of important applications. They are found mainly in the buildings materials (ramps, fences, doors, windows, patios, phonic isolations...), in automotive sector (dashboards, rear lockers, panels, doors and other internal accessories of vehicles...) where they not only reduce the mass of the component but also lower the energy needed for production by $80 \%$ [1], in consumer industries (furniture/cabinetry, floors, pallets, packaging or decorative moldings...) and in various applications (equipment of amusement parks, tables of picnics, game's modules, etc...). This craze to WPC is mainly due to their technical performances. Among them we can notice the enough good dimensional stability, good mechanical properties and acoustic performance, reduction of cost production and

*Conflict of interest: None declared.

${ }^{\#}$ Corresponding author. weight of items and their renewability. There is a considerable commercial interest in thermoplastic composites filled with wood fibers, due to the potential opportunities. The product has the aesthetic appearance of wood and the processing capability of thermoplastics and its performance in humid area. In spite of these attributes, disadvantages associated to the use of natural fibers as reinforcement in thermoplastics are the result of a lack of a good interfacial adhesion and a poor resistance to humidity absorption. The compatibility between the wood fibers and polymeric matrix constitutes one important factor in the production of WPCs with improved mechanical properties. Wood is hydrophilic in nature (with a high surface tension), which lowers its compatibility with hydrophobic polymeric materials (with a low surface tension) during composite preparation. The first key point for the production of acceptable WPC is the compatibility between fibers and the polymer. Properties of WPCs depend on the characteristics of matrix and fillers, chemical interaction between wood fibers and polymer, 
humidity absorption and processing conditions. The high level of moisture absorption of the wood beers and the poor adhesion with hydrophobic polymeric matrices (such as PP) can lead to deboning with age and to lowering mechanical properties. The three most important constituents of wood (cellulose, hemicellulose and lignin) are subject to low degradation temperature which can occur during processing. All these disadvantages can lead to debonding with age and produce a detrimental effect on the mechanical properties of the composites, both by changing the structure of the fiber and by producing volatile compounds that create micro voids across the interfaces. The need for coupling agents to improve fiber-matrix adhesion in such composites is well documented. The most commonly used coupling agent is maleic anhydride polypropylene (MAPP). The mechanical properties of wood fiber-polypropylene composites showed the best performance with the addition of 5\% (by wt.) of MAPP [2,3]. MAPP is also able to compensate for insufficient breakup forces during processing, such as low shear stress, by reducing the interfacial tension between PP and the cellulose, which leads to finer dispersion of the fiber throughout the system [4]. There are some studies on using other coupling agents such as silane [5,6] and isocyanates [7]. Recently, investigations have shown that the mechanical properties of WPCs can also be significantly improved by the addition of nanoclay to the composites $[8,9]$. The use of clay instead of MAPP is interesting in terms of the fire retardancy of the WPCs, which tend to burn quite easily; this is a heavy drawback. This is what justifies the use of clay and MAPP as coupling agent in our samples. Therefore, in this study, we examined the effects of MAPP and nanoclay, as coupling agent on the morphology and thermal behaviors of the WPCs. The dispersion of the functionalized filler into polypropylene matrix was performed. Another goal of this work is to characterize the thermo viscoelastic properties of this kind of WPC over a wide range of temperatures, which corresponds to the classical variations observed in the used domain of these materials. The rheological phenomena resulting from the high filler contents (e.g. high viscosity and complex stress-strain rate dependence) must be understood for proper formulation design and process control. Filler wetting, dispersion and wood-matrix polymer interactions are also important factors for WPC, because they strongly contribute to properties [10-14]. The rheological properties are studied as a function of the temperature and discussed in comparison to the behavior of neat PP. The performing materials of the future are based on the deep knowledge of the relationship: morphological structure - composition - properties. It is well established that the properties of these composites depend mainly on the characteristics of the polymer-filler interface.

\section{Experimental}

\subsection{Materials}

The basic materials used in this study are listed below. Polypropylene (PP) in the form of pellets from the Eastman Chemical Co. (Kingsport, TN) was used as the matrix. It had a melt flow index of $5.2 \mathrm{~g} / 10 \mathrm{~min}\left(\right.$ at $190^{\circ} \mathrm{C}$ and a $2.16 \mathrm{~kg}$ load) and a density of $0.910 \mathrm{~g} / \mathrm{cm}^{3}$. The wood flour particles of 425 microns (40-mesh) in size were kindly donated by American Wood fibers (Schofield, WI) and are constituted predominantly with ponderosa pine, maple, oak, spruce, southern yellow pine, cedar. The wood was oven dried at $100^{\circ} \mathrm{C}$ for $24 \mathrm{~h}$ before processing to remove moisture. The isotactic polypropylene matrix (PP) in the form of pellets was provided by Solvay Co from the Eastman Chemical Co. (Kingsport, $\mathrm{TN}$ ). It had a melt flow index of $5.2 \mathrm{~g} / 10 \mathrm{~min}\left(\right.$ at $190^{\circ} \mathrm{C}$ and a $2.16 \mathrm{~kg}$ load) with a density of $0.910 \mathrm{~g} / \mathrm{cm}^{3}$.

Polypropylene grafted with maleic anhydride (PPgMA) with an approximate maleic anhydride (MA) content of 3 wt.\% was purchased from Aldrich Chemical Company, Inc. (Milwaukee, WI). All ingredients were used as received.

\subsection{Compounding and Processing}

Before compounding, the wood flour was dried in an oven for at least $48 \mathrm{~h}$ at $105^{\circ} \mathrm{C}$ to a moisture content of less than $1 \%$ and then they were stored in a sealed plastic container to prevent the absorption of water vapor. First, the PP was put in the high-intensity mixer (Papenmeier, TGAHK20, Germany), and the reinforcement was added after the PP had reached its melting temperature. The mixing process took $10 \mathrm{~min}$ on average. After blending, the compounded materials were stored in a sealed plastic container. Several formulations were produced with various contents of PP, Wood flour, MAPP or clay. For the extraction of volatile and harmful gases, the hood was open. The different samples and their code are summarized in the following Table 1.

\subsection{Evaluation of the Composite Properties}

\subsubsection{Morphology Properties}

The state of dispersion of the wood inside the polymeric

Table 1. Composition and code of the samples (percentage is in weight).

\begin{tabular}{ccccc}
\hline Sample & PP (\%) & Wood (\%) & MAPP (\%) & Clay (\%) \\
\hline PP & 100 & 0 & 0 & 0 \\
WPPC 3 & 75 & 25 & 0 & 0 \\
WPPC4 & 50 & 50 & 0 & 0 \\
WPPCC & 45 & 50 & 0 & 5 \\
WPPCG & 45 & 50 & 5 & 0 \\
\hline
\end{tabular}


matrix was analyzed using optical microscopy on samples of $100-200 \mu \mathrm{m}$ thick. Scanning Electron Microscopy (SEM) was used to obtain microphotographs of the fracture surfaces of the wood composites. These fractures have been performed in liquid nitrogen to avoid any deformation. SEM has been performed using a FEI Quanta 400 microscope working at $30 \mathrm{kV}$ etched polymer surface was examined with LEICA optical microscope working in a transmission mode. Samples were thin enough that no special preparation of the samples was needed for their observations with the optical microscope.

\subsubsection{Thermal Analysis}

DSC is widely used to characterize the thermal properties of WPCs. DSC can measure important thermoplastic properties, including the melting temperature $\left(\mathrm{T}_{\mathrm{m}}\right)$, heat of melting, degree of crystallinity $\chi(\%)$, crystallization, and presence of recyclates/regrinds, nucleating agents, plasticizers, and polymer blends (the presence, composition, and compatibility). Thermal analysis of the WPC samples was carried out on a differential scanning calorimeter (Perkin Elmer Instruments, Pyris Diamond DSC, and Shelton, Connecticut) with the temperature calibrated with indium. All DSC measurements were performed with powdered samples of about $15 \pm 0.2 \mathrm{mg}$ under a nitrogen atmosphere with a flow rate of 20 $\mathrm{mL} / \mathrm{min}$. All samples were subjected to the same thermal experiment with the following thermal protocol, which was slightly modified from the one reported by Valentini et al. [15]:

1. First, the samples were heated from 40 to $200^{\circ} \mathrm{C}$ at a heating rate of $10^{\circ} \mathrm{C} / \mathrm{min}$ to eliminate any thermal history effect;

2. Second, the samples were cooled from 200 to $40.00^{\circ} \mathrm{C}$ at a cooling rate of $10^{\circ} \mathrm{C} / \mathrm{min}$ to detect the crystallization temperature $\left(\mathrm{T}_{\mathrm{c}}\right)$;

3. Finally, the samples were heated from $40^{\circ} \mathrm{C}$ to $180^{\circ} \mathrm{C}$ at a heating rate of $10^{\circ} \mathrm{C} / \mathrm{min}$ to determine $\mathrm{T}_{\mathrm{m}} . \mathrm{T}_{\mathrm{m}}$ and the heat of fusion $\left(\Delta H_{m}\right)$ were obtained from the thermograms during the second heating. The values of $\Delta H_{m}$ were used to estimate $\chi(\%)$, which was adjusted for each sample in $\chi_{\text {cor }}(\%)$ based on the percentage of polypropylene in the composite. The degree of crystallinity $\left(\chi_{c o r}\right)$ of the PP component was determined from the following equation $[16,17]$ :

$$
\chi_{\text {cor }}(\%)=\frac{\Delta H_{m}(J / g)}{(1-M F) \Delta H_{0}(J / g)}
$$

where $\Delta H_{m}$ and $\Delta H_{0}$ are the heat of fusion of the composites and $100 \%$ crystalline polypropylene respectively. In this calculation, $\Delta H_{0}$ is taken to be $190(\mathrm{~J} / \mathrm{g})$ [18].

\subsubsection{Melt Rheological Measurements}

Background

The viscoelastic behavior of molten polymers can be determined using oscillatory rheological experiments such as dynamic mechanical testing, which offers a convenient way to assess frequency dependence of mechanical properties of polymers.

An oscillatory strain is applied and the resulting stress is measured. By the deconvolution of the stress-strain rate in-phase and the out-of-phase components, both real part and imaginary one of the complex shear viscosity $\eta^{*}$ can be determined.

$$
\eta_{(\omega)}^{*}=\eta_{(\omega)}^{\prime}-j \eta_{(\omega)}^{\prime \prime}
$$

where

$\eta^{*}$ is the complex viscosity,

$\eta^{\prime}$ is the loss viscosity,

$\eta^{\prime \prime}$ is the storage viscosity,

$\omega$ is the pulsation of the frequency:

$$
\omega=2 \pi \mathrm{N}
$$

Then, the real component of the complex viscosity $\left(\eta^{\prime}\right)$ describes the viscous dissipation in the sample, while the imaginary component $\left(\eta^{\prime \prime}\right)$ represents the stored elastic energy. Furthermore, the tangent of the phase angle $(\tan \delta)$ describes the balance between the viscous and elastic behaviors in a polymer melt:

$$
\tan \delta=\eta^{\prime} / \eta^{\prime \prime}
$$

Another useful representation is to plot the experimental frequency sweep data points in the complex plane. That means that imaginary part (of the complex viscosity) $\eta^{\prime}$ values are reported along the abscissa ( $\mathrm{X}$ axis) and the imaginary ones $\left(\eta^{\prime \prime}\right)$ in ordinate (Y axis). Usually, the experimental points are located on arc of circle characteristic for a Cole-Cole distribution. The extrapolation of this arc of circle to the zero ordinate value gives the Newtonian viscosity which is related to the average molecular weight $\mathrm{Mw}$ of the considered polymer through a power law: $\left(\eta_{0}=\mathrm{K} .\left(\mathrm{M}_{\mathrm{w}}\right)^{3.4}\right)[19]$.

Melt rheological measurements of neat PP and PPwood composites were carried out at $180^{\circ} \mathrm{C}$ with an ARES Rheometer Scientific mechanical spectrometer in oscillatory frequency sweep mode with a parallel-plates measuring cell. The diameter of the plates was $8 \mathrm{~mm}$ and the gap was $1.5 \mathrm{~mm}$. The rheological properties of the wood polymer composite melts were measured at $200^{\circ} \mathrm{C}$; the frequency was ranged from $0.1 \mathrm{rad} / \mathrm{s}$ to $100 \mathrm{rad} / \mathrm{s}$. The imposed oscillatory shear strain amplitude was tested for each temperature to valid all the measurements inside the linear viscoelastic domain.

\section{Results and Discussions}

\subsection{SEM Results}

The morphologies of the fracture surface of different 
composites were presented in Figure 1. Examination of all composites under SEM magnification reveals the occurrence of a heterogeneous matrix composed of areas of predominately PP and areas of wood particles embedded in the PP. It is possible to observe deep cavities and distinct gaps at higher magnifications of the $1^{\text {st }}$ specimen indicating poor adhesion. It has also some gaps and pullouts between the reinforcement fibers and the polymer matrix in the overview micrographs of the two last ones. Micrographs taken from the fractured surface of all the specimens showed different organization of the fibers in the composites, depending on the content of wood flour and the presence or not of coupling agent (MAPP or clay). When comparing WPPC3 to all other samples, we see that the surface of WPPC3 is much smoother and there's less aggregates. Most of the wood fiber was enveloped by the polymer matrix (i.e. the weight ratio of the polymer $(75 \%)$ is higher than that of wood $(25 \%))$. There is less wood in WPPC3 and the molten polymer can quite well encapsulate the particles of wood flour. In the other ones, when the rate of wood increases, it appears a poor interfacial adhesion between the filler and the matrix. This shows that the morphology is depending on the rate of wood incorporated. The incorporation of filler into the polymer matrix disrupted the homogeneity of the matrix. Particles did not adhere very well to the surface of polymeric matrix that cracks and voids can be observed around the particles clearly (Figure 1(b)). The composites exhibited interfacial debonding with the appearance of voids and fiber pullout with further increases in the wood-flour content (Figures 1(b)-(d)). This phenomenon is more accented in Figure 1(b) having only wood and PP. The non-coupled composite (Figure 1(b)) displayed a rough morphology with the presence of many voids and cavities resulting from fiber pullout. This indicates poor interfacial adhesion, thus revealing the low affinity between the polymer matrix and the wood-flour filler. Water can be easily absorbed by the voids and
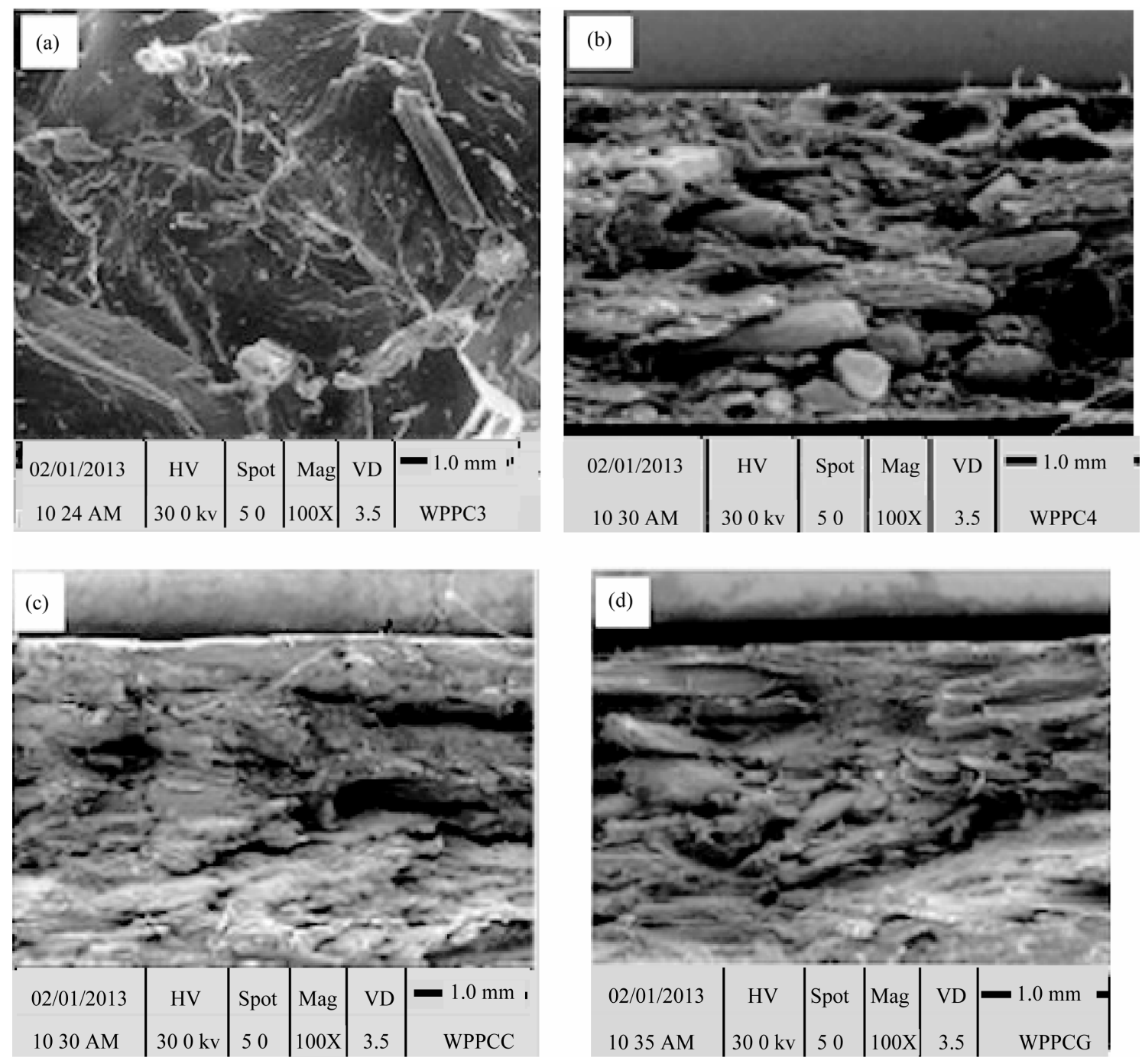

Figure 1. SEM micrograph of composites: (a) WPPC3; (b) WPPC4; (c) WPPCC; (d) WPPCG. 
cavities, thus explaining the high level of moisture absorption found for the non-coupled composite in our past studies [3]. The addition of clay in the formulation led to the improvement of the fiber dispersion, as shown in Figure 1(c). This dispersion was even better when MAPP replaced the clay (comparison of Figure 1(c) with Figure 1(d)). Comparing Figure 1(d) and the others ones, one can see that the presence of MAPP greatly improved the homogeneity of the blends. Strong interfacial shear strength between the filler and the matrix was observed; this indicated that the presence of MAPP helped to bind the two phases together. Some of the $\mathrm{OH}$ groups of wood flour reacted with maleic anhydride to form linkages and, thereby, improved the dispersion of wood in the composites. In our previous studies, it has been shown that the addition of MAPP in the composite showed improved fiber matrix adhesion [20]. It was also observed that the layers of the matrix material were pulled out together with the fibers during fracture. This indicated better interfacial adhesion, and further supported the higher mechanical properties of WPC with MAPP. Studies have shown that the presence of wood flour favors the separation of clay platelets [9]. Additionally, the clay platelets could be separated with the forced orientation of the extruder, which accounted for the good dispersion obtained when clay was added. Nevertheless, the possibility of replacing MAPP with clay appears to be interesting because the combination of wood flour with the polymeric matrix made the composite more sensitive to flame. So far, halogenated flame retardants, such as organic brominated compounds, are generally used to improve the flammability of composites, but they usually increase both smoke and carbon monoxide yield rates, which is catastrophic for the environment. Clay, when used instead of MAPP, may play the role of flame retardant and also improve the mechanical properties. The rule of clay is not negligible; the chemical structure of this additive allows combining the function of dispersing and coupling agents, so it is capable of bonding the filler and PP matrix by chemical bonds. Hence, mechanical properties are improved. Meanwhile flame retardancy could also be improved [21-24].

\subsection{DSC Results}

The thermal properties and crystallization behavior of PP and composites were analyzed by DSC. The results of crystallization temperature $\left(\mathrm{T}_{\mathrm{c}}\right)$, heat of crystallization $\left(\Delta H_{c}\right)$, melt temperature $\left(\mathrm{T}_{\mathrm{m}}\right)$ and the degree of crystallinity $\chi_{\text {cor }}(\%)$ from DSC were summarized in the following Table 2.

Figure 2 shows the DSC thermograms of cooling (Figure 2(a)) and melting (Figure 2(b)) curves of PP and composites. The presence of MAPP or wood flour showed significant effects on the cooling behavior of the
Table 2. Thermal properties of PP and its composites.

\begin{tabular}{cccc}
\hline Sample & $\mathbf{T}_{\mathbf{m}}\left({ }^{\circ} \mathrm{C}\right)$ & $\mathbf{T}_{\mathbf{c}}\left({ }^{\circ} \mathrm{C}\right)$ & $\chi_{\text {cor }}(\%)$ \\
\hline PP & 165.2 & 119.5 & 37.9 \\
WPPC3 & 170.0 & 124.4 & 41.1 \\
WPPC4 & 169.7 & 123.7 & 38.8 \\
WPPCC & 170.5 & 123.8 & 38.5 \\
WPPCG & 165.5 & 126.5 & 42.3 \\
\hline
\end{tabular}
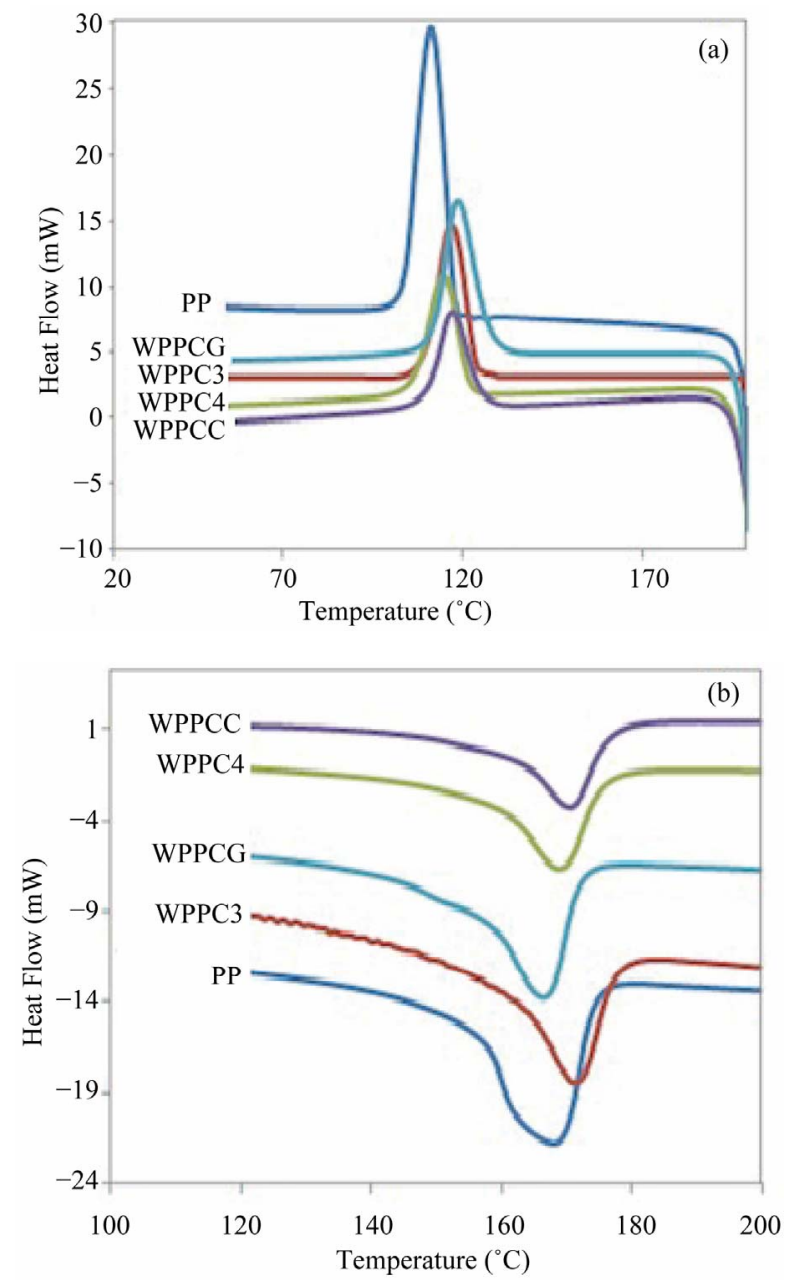

Figure 2. DSC curves of neat PP and its composites: (a) Cooling; (b) Melting.

composites. Only one exothermic peak was registered for all the samples. For neat PP processed the crystallization peak was observed at around $\mathrm{T}_{\mathrm{c}}=120.5^{\circ} \mathrm{C}$ while for the composites these exothermic peaks shifted to higher temperatures in all cases. The determined $T_{c}$ values are shown in Table 2. The higher $T_{c}$ values of the composites indicate that the crystallization is favored in the presence of MAPP or wood particles. The results imply that MAPP and wood acted as precursor and increased crystallization; it is due to the nucleation effect of MAPP or wood: fibers act as sites for heterogeneous nucleation 
thus inducing the crystallization of the matrix $[25,26]$.

The results also indicate that the addition of fiber increased crystallinity of the test materials. This is attributed to the nucleation effect of the fibers which provide nucleation sites and facilitate crystallization of the polymer as well as transcrystallinity [27].

The same observation was reported in flax fiber/PP $[28,29]$. It was reported that clay, especially the exfoliated clay, increased the crystallization temperature and acted as a nucleating agent $[30,31]$.

The use of the MAPP instead clay seems to have enhanced the level of crystallinity in the composites for the same levels of wood loading and also accelerates the crystallization.

Figure 2(b) shows the heating thermograms of PP and its composites obtained from the second heating range. For all the samples only one single endothermic peak was observed at similar temperatures (near $165^{\circ} \mathrm{C}$ ), corresponding to the melting of the $\alpha$-crystalline phase of the PP sequences. The peak area of neat PP was larger than that of composites. The area of melting peak diminished in all the composites. However after normalizing the melting enthalpy with respect to the fraction of PP in the composites (Table 2) it was possible to verify that the melting peak showed a significant increase. The possible reason is that wood fibers may restrict the flow ability of PP molecules during the melting process. Calculations based on the extrapolated melting enthalpy for a $100 \%$ crystalline sample lead to the degree of crystallinity, $\chi_{\text {cor }}(\%)$ reported in Table 2 . These results confirmed the behavior observed during heating that the filler favors the crystallization of the polymer matrix probably due to the creation of nuclei on the filler surface that induce the formation of a transcrystalline layer [25].

Nevertheless, the possibility of replacing MAPP with clay appears to be interesting because the combination of wood flour with the polymeric matrix made the composite more sensitive to flame [32]. So far, halogenated flame retardants, such as organic brominated compounds, are generally used to improve the flammability of composites, but they usually increase both smoke and carbon monoxide yield rates, which is catastrophic for the environment. Clay, when used instead of MAPP, may play the role of flame retardant and also improve the thermal stability of the composite which is in accordance with our study. In Figure 2(b), WPPCC (sample with clay) has the highest melting temperature, which demonstrates its greater thermal stability. Another feature of these results is the decrease of the peaks accompanied by a reduction of its width in all the composites. It was reported that clay, especially the exfoliated clay, increased the crystallization temperature and acted as a nucleating agent. Compared to the neat PP, the wood/PP composites displayed a better thermal stability. The use of these composites shows a potential for promising applications in cost-effective composites with enhanced mechanical and thermal properties.

\subsection{Rheological Results}

Figure 3 shows the variations of the real and the imaginary parts of the complex viscosity for neat polypropylene. Moreover the complex plane diagram is also plotted onto this figure. The extrapolation of the best fit of the arc of circle through the experimental set of points $\left(\eta^{\prime}, \eta^{\prime \prime}\right)$ lead to a value of $3500 \mathrm{~Pa}$.s for the Newtonian viscosity $\eta_{0}$ of the virgin $\mathrm{PP}$ at $\mathrm{T}=180^{\circ} \mathrm{C}$. This value will serve us as a reference to exemplify the changes observed with wood PP composites.

On Figure 4 are drawn the frequency variations of both the loss and the storage viscosities (Real and imaginary parts of the complex viscosity) measured at $\mathrm{T}=$ $180^{\circ} \mathrm{C}$ for all samples. Obviously, all the composites materials exhibit viscoelastic values greater than those for neat PP. Moreover one can notice several orders of magnitude for the changes in these values (about two decades). The closer to the unfilled PP is the sample with the lower concentration of wood filler (WPPC3).
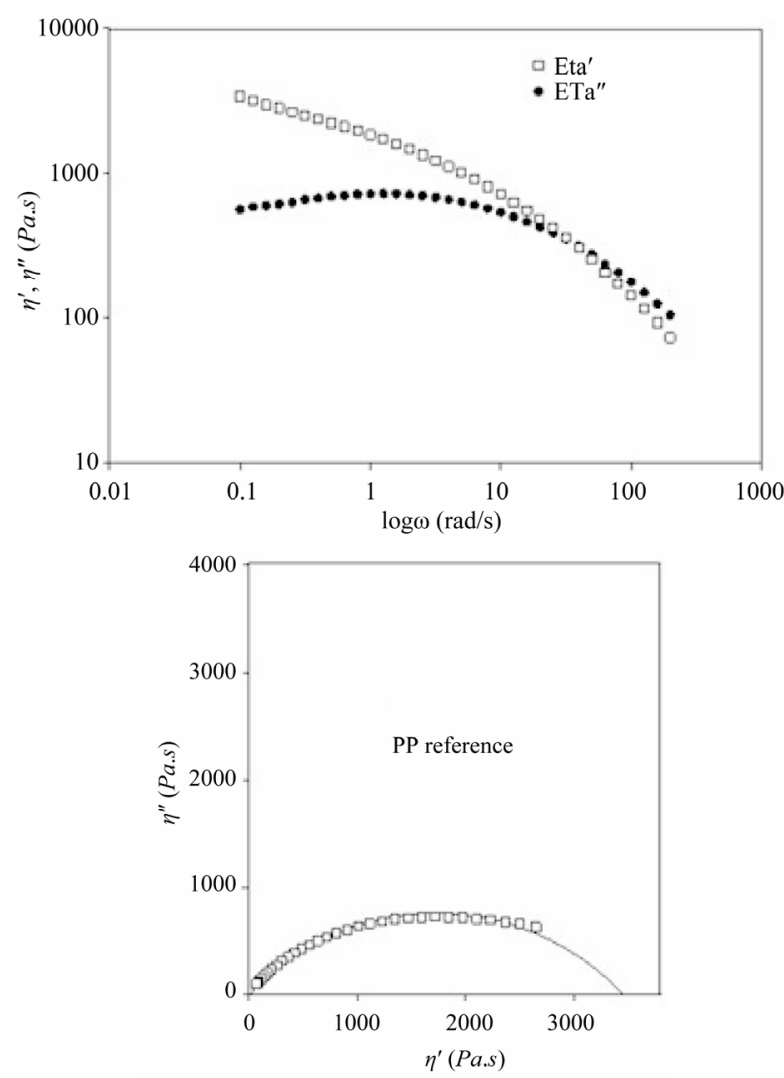

Figure 3. Frequency variations of the loss $\left(\eta^{\prime}\right)$ and the storage $\left(\eta^{\prime \prime}\right)$ viscosities (upper figure) and complex plane representation (bottom figure) at $T=180^{\circ} \mathrm{C}$ for neat $\mathrm{PP}$ ( $\eta^{\prime \prime}$ versus $\left.\eta^{\prime}\right)$. 

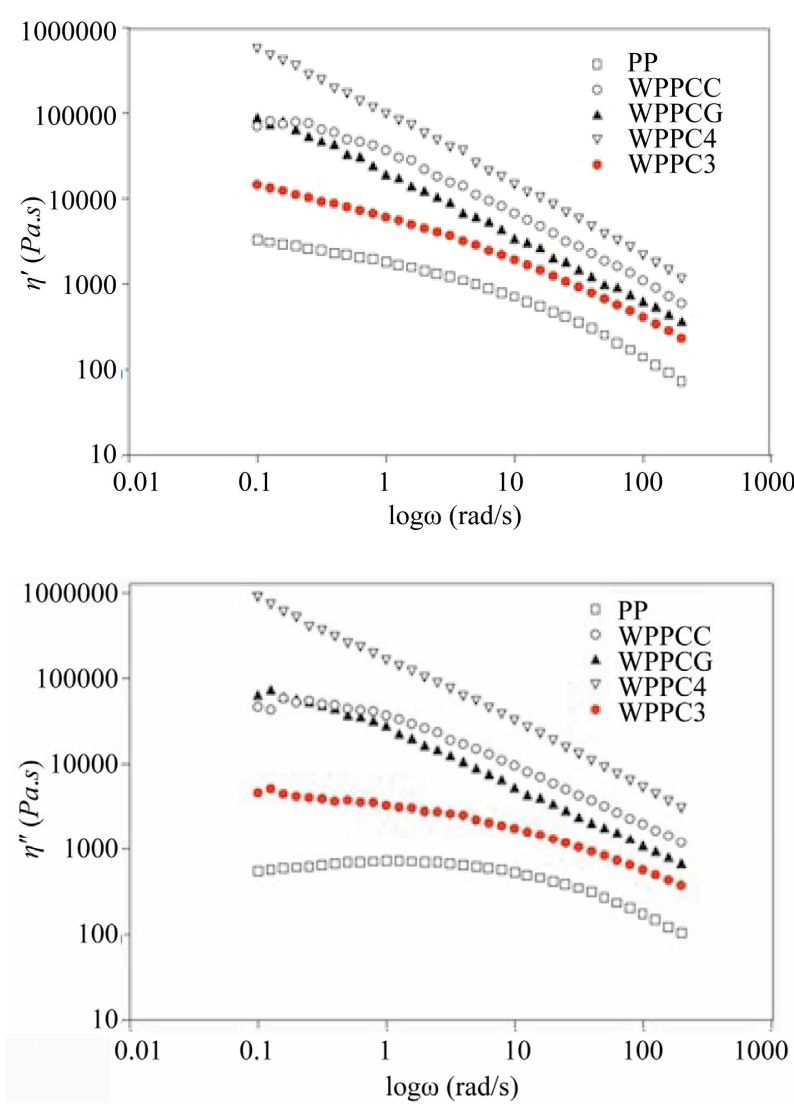

Figure 4. Frequency variations of the loss $\left(\eta^{\prime}\right)$ and the storage $\left(\eta^{\prime \prime}\right)$ viscosities for neat $P P$ and its composites at $T=$ $180^{\circ} \mathrm{C}$.

Figure 5 represents the complex plane variations for the neat PP and the wood polypropylene composites. Again, great changes are observed for WPP regarding the reference PP. However, for samples WPPC3, WPPCG and WPPCC the circular variation seems still quite valid. Sample WPPC4 exhibits a deviation to the circular behavior and shows a linear variation of the storage viscosity versus the loss viscosity. This is characteristic for a gel behavior indicating then a high level of interaction between the matrix and the filler however no compatibilizer is used; Table 3 reports the Newtonian values determined for all the samples:

WPPC4 exhibits the higher viscoelastic behavior but it contains $50 \%$ wood filler and $50 \%$ PP matrix while samples WPPCC and WPPCG contain only $45 \%$ PP matrix and $50 \%$ Wood filler. Thus in the second case the ratio matrix/filler is less than $1(0.9)$ while it is 1 in the first case. If we compare samples with the same ratio (WPPCC and WPPCG) we can notice that the higher Newtonian viscosity is obtained with the sample containing MAPP as comptabilizer. Then the addition of a small concentration of nanoparticles like nanoclays does not improve the resulting melt viscoelastic behavior of the wood polymer composite.

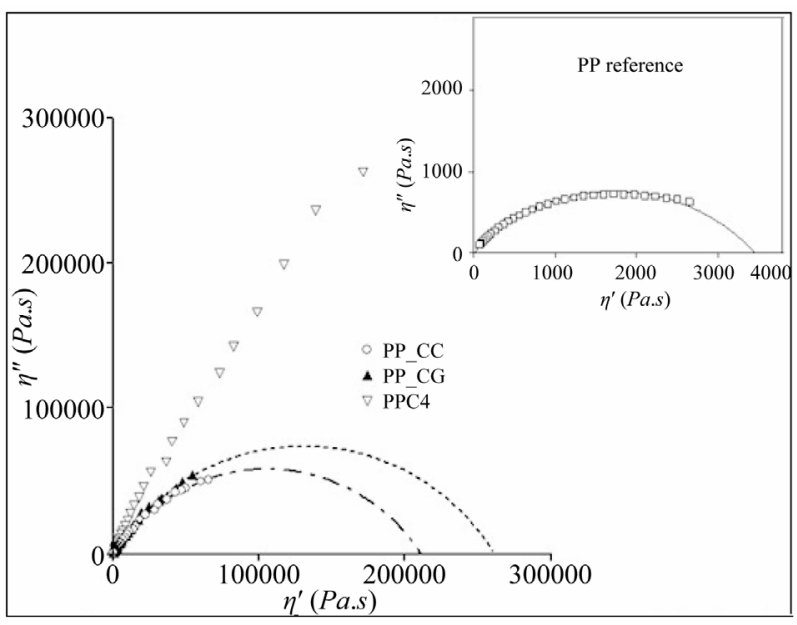

Figure 5. Complex plane diagrams for all the WPC (upper right curve: complex plane diagram for neat $\mathrm{PP}$ ) at $\mathrm{T}=$ $180^{\circ} \mathrm{C}$.

Table 3. Newtonian values for WPC composites.

\begin{tabular}{cccccc}
\hline Sample & PP (\%) & Wood (\%) & MAPP (\%) & Clay (\%) & $\boldsymbol{\eta}_{\mathbf{0}}$ (Pa.s) \\
\hline PP & 100 & 0 & 0 & 0 & 3500 \\
WPPC 3 & 75 & 25 & 0 & 0 & 22,500 \\
WPPC4 & 50 & 50 & 0 & 0 & $\infty$ \\
WPPCC & 45 & 50 & 0 & 5 & 210,000 \\
WPPCG & 45 & 50 & 5 & 0 & 260,000 \\
\hline
\end{tabular}

\section{Conclusions}

The polymer matrix in none coupled composites was not continuously distributed and most of the wood fibers directly contacted one another, thus resulting in poor adhesion at the interface. The presence of the coupling agents changed the morphology of the materials. The addition of MAPP or clay to the composites produced a more homogeneous surface with less voids and cavities. This indicated that these coupling agents have a positive effect on the interfacial adhesion between the filler and the matrix. Melt rheology confirms this behavior. The comptabilizer induces a better interface between the fillers and the matrix. However, the effect of the compatibilizer is more efficient than this of the nanoclay. But it is difficult to discriminate one effect from another. It should be interesting to study wood filler polypropylene composites containing both the comptaibilizer (Maleic anhydride) and the nanoclay in different proportions. This will be a further development of this study. The sample with the higher amount of wood filler $(50 \%)$ exhibits the higher viscoelastic behavior; however, it does contain neither compatibilizer nor nanoclay. In such a case, we can observe a change in the flow regime from a linear entangled melt flow to a gel flow. The consequence is the very high magnitude of change in the vis- 
cosity values that can lead to difficulties in the further processing operations. The thermal degradation trends of both kinds of composites were similar and increased the thermal stability of PP in comparison to the neat PP. The cooling process shows an increase in the crystallization temperature of PP with the addition of fillers. This phenomenon may be attributed to the fillers being dispersed in PP matrix, promoting the heterogeneous nucleation.

Finally, the success of WPP composites lies in the compromise between the high level of interaction between the filler and the matrix to improve the solid state mechanical properties on the condition that the melt viscosity range of the blends will render them still processable. Then a development of this work would be to process high fluidity WPP with a high content of wood filler and a high level of interaction.

\section{Funding}

This research received no specific grant from any funding agency in the public, commercial or not for profit sectors.

\section{REFERENCES}

[1] R. Malkapuram, K. Vivek and Y. S. Negi, "Novel Treated Pine Needle Fiber Reinforced Polypropylene Composites and Their Characterization," Journal of Reinforced Plastics and Composites, Vol. 28, No. 10, 2009, pp. 11691175. http://dx.doi.org/10.1177/0731684407087759

[2] A. K. Bledzki and O. Faruk, "Wood Fibre Reinforced Polypropylene Composites: Effect of Fibre Geometry and Coupling Agent on Physico-Mechanical Properties," Applied Composite Materials, Vol. 10, No. 6, 2003, pp. 351-356. http://dx.doi.org/10.1023/A:1025741100628

[3] D. Ndiaye, L. M. Matuana, S. Morlat-Thérias, J. L. Gardette and A. Tidjani, "Thermal and Mechanical Properties of Polypropylene/Wood-Flour Composites," Journal of Applied Polymer Science, Vol. 119, No. 6, 2011, pp. 3321-3328. http://dx.doi.org/10.1002/app.32985

[4] K. Kyu-Nam, K. Hyungsu and L. Jae-Wook, "Effect of Interlayer Structure, Matrix Viscosity and Composition of a Functionalized Polymer on the Phase Structure of Polypropylene-Montmorillonite Nanocomposites," Polymer Engineering \& Science, Vol. 41, No. 11, 2001, pp. 19631969. http://dx.doi.org/10.1002/pen.10892

[5] T. J. Keener, R. K. Stuart and T. K. Brown, "Maleated Coupling Agents for Natural Fibre Composites," Composites Part A: Applied Science and Manufacturing, Vol. 35, No. 3, 2004, pp. 357-362.

http://dx.doi.org/10.1016/j.compositesa.2003.09.014

[6] M. Bengsson and K. Oksman, "Silane Crosslinked Wood Plastic Composites: Processing and Properties," Composites Science and Technology, Vol. 66, No. 13, 2006, pp. 2177-2186.

http://dx.doi.org/10.1016/j.compscitech.2005.12.009

[7] R. G. Raj, B. V. Kokta, D. Maldas and C. Deneault, "Use of Wood Fibers in Thermoplastics. The Effect of Coupling Agents in Polyethylene-Wood Fiber Composites", Journal of Applied Polymer Science, Vol. 37, No. 4, 1989, pp. 1089-1103.

http://dx.doi.org/10.1002/app.1989.070370420

[8] O. Faruk and L. M. Matuana, "Nanoclay Reinforced HDPE as a Matrix for Wood-Plastic Composites," Composites Science and Technology, Vol. 68, No. 9, 2008, pp. 20732077. http://dx.doi.org/10.1016/j.compscitech.2008.03.004

[9] Y. Zhong, T. Poloso, M. Hetzer and D. Kee, "Enhancement of Wood/Polyethylene Composites via Compatibilization and Incorporation of Organoclay Particles," Polymer Engineering \& Science, Vol. 47, No. 6, 2007, pp. 797-803. http://dx.doi.org/10.1002/pen.20756

[10] B. V. Kokta, R. G. Raj and C. Deneault, "Use of Wood Flour as Eller in Polypropylene: Studies on Mechanical Properties," Polymer-Plastics Technology and Engineering, Vol. 28, No. 3, 1989, pp. 247-259. http://dx.doi.org/10.1080/03602558908048598

[11] G. E. Meyers, C. Clemens, J. J. Balatinecz and R. T. Woodhams, "Effects of Composition and Polypropylene Melt Flow on Polypropylene-Waste Newspaper Composites," Proceeding of the Annual Technical Conference, No. 50, 1992, pp. 602-604.

[12] P. W. Balasuriya, L. Ye and Y. W. Mai, "Mechanical Properties of Wood Flake-Polyethylene Composites. Part I. Effects of Processing Methods and Matrix Melt Flow Behavior," Composites, Part A, Vol. 32, 2001, pp. 619629. http://dx.doi.org/10.1016/S1359-835X(00)00160-3

[13] J. Z. Lu, Q. Wu and H. S. McNabb, "Chemical Coupling in Wood Beer and Polymer Composites: A Review of Coupling Agents and Treatments," Wood and Fiber Science, Vol. 32, 2000, pp. 88-104.

[14] T. Q. Li and R. K. Y. Li, "Impact Behavior of Sawdust/ Recycled-PP Composites," Journal of Applied Polymer Science, Vol. 81, No. 6, 2001, pp. 1420-1428. http://dx.doi.org/10.1002/app.1567

[15] L. Valentini, J. Biagiotti, J. M. Kenny and S. Santucci, "Morphological Characterization of Single-Walled Carbon Nanotubes-PP Composites," Composites Science and Technology, Vol. 63, No. 8, 2003, pp. 1149-1153. http://dx.doi.org/10.1016/S0266-3538(03)00036-8

[16] L. Mandelkern, "Crystallization of Polymers," Series in Advanced Chemistry, McGraw-Hill, New York, 1964.

[17] E. M. Norma and M. A. Villar, "Thermal and Mechanical Characterization of Linear Low-Density Polyethylene/ Wood Flour Composites," Journal of Applied Polymer Science, Vol. 90, No. 10, 2003, pp. 2775-2784. http://dx.doi.org/10.1002/app.12934

[18] V. Hristov and S. Vasileva, "Dynamic Mechanical and Thermal Properties of Modified Polypropylene Wood Fiber Composites," Macromolecular Materials and Engineering, Vol. 288, No. 10, 2003, pp. 798-806. http://dx.doi.org/10.1002/mame.200300110

[19] A. Kumar, S. Commereuc and V. Verney, "Thermal and Dynamic Mechanical Characterization of PolypropyleneWood Flour Composites," Polymer Degradation and Stability, Vol. 85, 2004, pp. 751-757.

http://dx.doi.org/10.1016/j.polymdegradstab.2003.11.014 
[20] D. Ndiaye, E. Fanton, S. Morlat-Thérias, J. L. Gardette and A. Tidjani, "Durability of Wood Polymer Composites: Part 1. Influence of Wood on the Photochemical Properties," Composites Science and Technology, Vol. 68, No. 13, 2008, pp. 2779-2784. http://dx.doi.org/10.1016/i.compscitech.2008.06.014

[21] G. Marosi, A. Tohl, G. Bertalan, P. Anna, M. A. Maatoug, I. Ravadits, I. Bertol and A. Toth, "Modified Interfaces in Multicomponent Polypropylene fibers," Composites Part A: Applied Science and Manufacturing, Vol. 29A, No. 9-10, 1998, pp. 1305-1311. http://dx.doi.org/10.1016/S1359-835X(98)00047-5

[22] I. Ravadits, A.Toth, G. Marosi, A. Marton and A. Szep, "Organosilicon Surface Layer on Polyolefins to Achieve Improved Flame Retardancy through an Oxygen Barrier Effect," Polymer Degradation and Stability, Vol. 74, No. 3, 2001, pp. 419-422. http://dx.doi.org/10.1016/S0141-3910(01)00179-3

[23] P. Anna, G. Marosi, S. Bourbigot, M. Lebras and R. Delobel, "Intumescent Flame Retardant System of Modified Rheology," Polymer Degradation and Stability, Vol. 77, No. 2, 2002, pp. 243-247. http://dx.doi.org/10.1016/S0141-3910(02)00040-X

[24] B. Li and J. He, "Investigation of Mechanical Property, Flame Retardancy and Thermal Degradation of LLDPE Wood-Fibre Composites," Polymer Degradation and Stability, Vol. 83, No. 2, 2004, pp. 241-246. http://dx.doi.org/10.1016/S0141-3910(03)00268-4

[25] K. Na, H. S. Park, H. Y. Won, J. K. Lee, K. H. Lee, J. Y. Nam and B. S. Jin, "SALS Study on Transcrystallization and Fiber Orientation in Glass Fiber/Polypropylene Composites", Macromolecular Research, Vol. 14, 2006, pp. 499-503. http://dx.doi.org/10.1007/BF03218715

[26] M. Pracella, D. Chionna, I. Anguillesi, Z. Kulinski and E. Piorkowska, "Functionalization, Compatibilization and
Properties of Polypropylene Composites with Hemp Fibres," Composites Science and Technology, Vol. 66, No. 13, 2006, pp. 2218-2230. http://dx.doi.org/10.1016/j.compscitech.2005.12.006

[27] U. Somnuk, G. Eder, P. Phinyocheep, N. Suppakarn, W. Sutapun and Y. Q. Ruksakulpiwat, "Crystallization of Natural Fibers-Polypropylene Composites," Journal of Applied Polymer Science, Vol. 106, No. 5, 2007, pp. $2997-$ 3006. http://dx.doi.org/10.1002/app.26883

[28] N. E. Zafeiropoulos, D. R. Williams and C. A. Baillie, "Engineering and Characterization of the Interface in Flax Fibre/Polypropylene Composite Materials. Part I. Development and Investigation of Surface Treatments," Composites Part A: Applied Science and Manufacturing, Vol. 33, No. 8, 2002, pp. 1083-1093. http://dx.doi.org/10.1016/S1359-835X(02)00082-9

[29] A. Arbelaiz, B. Fernandez, J. A. Ramos, et al., "Thermal and Crystallization Studies of Short Flax Fibre Reinforced Polypropylene Matrix Composites: Effect of Treatments," Thermochimica Acta, Vol. 440, No. 2, 2006, pp. 111-121. http://dx.doi.org/10.1016/j.tca.2005.10.016

[30] T. G. Gopakumar, J. A. Lee, M. Kontopoulou and J. S. Parent, "Influence of Clay Exfoliation on the Physical Properties of Montmorillonite/Polyethylene Composites," Polymer, Vol. 43, No. 8, 2002, pp. 5483-5491. http://dx.doi.org/10.1016/S0032-3861(02)00403-2

[31] H. Zhai, W. Xu, H. Guo, Z. Zhou, S. Shen and Q. Song, "Preparation and Characterization of PE and PE-g-MAH/ Montmorillonite Nanocomposites," European Polymer Journal, Vol. 40, No. 11, 2004, pp. 2539-2545. http://dx.doi.org/10.1016/j.eurpolymj.2004.07.009

[32] S. Borysiak, D. Paukszta and M. Helwig, "Flammability of Wood-Polypropylene Composites," Polymer Degradation and Stability, Vol. 91, No. 12, 2006, pp. 3339-3343. http://dx.doi.org/10.1016/j.polymdegradstab.2006.06.002 